Research Article

\title{
Bubble Bursting and Drainage Characteristics at the Free Surface of a Liquid Pool with an Aerosol
}

\author{
Xiang Yu $(\mathbb{D}$, Haifeng Gu $(\mathbb{D}$, Weikai Yin $(\mathbb{D}$, and Qingyang Sun \\ Heilongjiang Provincial Key Laboratory of Nuclear Power System \& Equipment, Harbin 150001, China \\ Correspondence should be addressed to Haifeng Gu; guhaifeng1980@163.com
}

Received 29 June 2020; Accepted 16 September 2020; Published 16 October 2020

Academic Editor: Han Zhang

Copyright (c) 2020 Xiang Yu et al. This is an open access article distributed under the Creative Commons Attribution License, which permits unrestricted use, distribution, and reproduction in any medium, provided the original work is properly cited.

\begin{abstract}
When nuclear reactor accidents such as steam generator pipe ruptures or core melting occur, radioactive aerosols will remain in the liquid pools. Bubbles may be generated by boiling or gas injection. Film droplets produced by bubble bursts may entrain radioactive aerosols from the liquid to the air. This long-lasting behavior can produce a considerable amount of aerosols. To evaluate radioactive source terms, many physical quantities related to bubble bursting need to be determined, such as bubble burst position, bubble lifetime, cap film roll-up velocity, and cap film thickness, which are very important parameters that influence the releasing of radioactive aerosols. In this research, the phenomenon of bubble bursting was investigated by visualization. The above parameters were measured. We obtained the lifetime distribution of bubbles under different conditions, and we found that the addition of an aerosol increased the lifetime of the bubbles. By comparing the bubble lifetime to the roll-up velocity and cap thickness, we showed that the increase of the liquid temperature thickened the cap at rupture and the increase of the air temperature thinned the cap. The addition of an aerosol increased the film rollup velocity.
\end{abstract}

\section{Introduction}

Bubbles exist widely in industrial and environmental processes. Bubbles burst after reaching a free surface for a period of time. The resulting droplets, as part of a key liquid-gas conversion process, have a wide range of impacts on our daily lives [1]. For example, bubbles in sea water are the basic conditions for the formation of white ocean waves [2]. The sea salt aerosol produced by the rupturing of these waves has a greater impact on cloud formation, radiation transmission, and marine meteorology [3], further affecting the global climate [4]. The bursting of bubbles may also cause the spread of microorganisms such as pathogens. Pathogen-laden drops smaller than $10 \mu \mathrm{m}$ may enter the respiratory tract and cause viral infection [5]. For the aspect of nuclear power, the research of bubble bursting behavior mainly focuses on the entrainment phenomenon in a steam generator, i.e., gas-water separation [6] and radioactive aerosol release in a severe reactor accident [7]. When fuel cladding meltdown occurs in a reactor, a large number of fission products are released from the molten fuel, of which aerosol is more important. When a primary steam pipe ruptures, the primary circuit system may be contaminated with suspended or dissolved radionuclides, and the interaction between the melt and the concrete may generate radioactive aerosols. The above methods for releasing radioactive materials into containment are called radioactive "source terms." With the help of natural and engineered fission product removal mechanisms, radioactive aerosols may be retained in the bulk [8]. Owing to the existence of decay heat or pressure relief, bubbles may be generated in a liquid pool. In a filtered containment venting system (FCVS), bubbles may also be generated from the injection of gas into a liquid. The bubbles will rise to the free surface, and droplets generated from the rupture of bubbles may entrain the aerosol in a liquid pool into the air [9].

The shape of the bubbles floating up above a liquid surface will eventually affect the drainage characteristics. 
Toba [10] used numerical methods to calculate the dimensionless parameters of bubbles floating on a free liquid surface, which were divided into three parts. Toba also calculated the expressions of the volume of each portion. As a bubble radius increases, the volume of the bubble above a liquid surface will become larger. The Bo number can be used to characterize the floating state of bubbles. Besides, the larger the Bo number, the larger the volume above the liquid surface [11]. At the same time, the Bo number can also be used to characterize the drainage characteristics. When Bo $<0.25$, the drainage is mainly driven by capillary force. When Bo $>0.25$, the drainage is mainly driven by gravity [12].

After a bubble rises to a free surface, it will rupture after a period of time. The time interval between the arrival on the free surface and bursting can be defined as the bubble lifetime. The bubble lifetime has proven to be related to air temperature and humidity [2,13] bubble diameter [14], etc. The effect of soluble insoluble aerosols on experimental results remains unclear [1].

The reason for bubble bursting has been investigated. Thermal fluctuations or van der Waals forces may cause a film to rupture when the film thins to a certain thickness [15]. Convection cell emission from marginal pinching regions, e.g., marginal regeneration, is the fundamental reason for bubble bursting by nucleating a hole in film [16]. By observing the rupture of bubbles with surfactant, it was determined that the marginal regeneration and gravity drainage jointly caused the bubbles to burst [17]. The disturbance inside a bubble was more likely to cause the bubble to burst than the external impact, and the aging of the bubble was the external cause that eventually caused the bubble to burst [1]. The bubble began to rupture by forming a hole on the cap. The force balance of the bubble was broken, and the liquid film rolled up and then formed liquid ligaments [18] with Rayleigh-Taylor mechanism [16]. Then, the film dropped and jet drops were generated $[19,20]$. The puncture position, e.g., the location of the hole, the ratio of the horizontal length of the rupture point to the edge of cap to cap film radius [21], the angle between the line connecting the puncture point and the bubble fitting circle center and the free surface [17], the angle between the line connecting the puncture point and the bubble fitting circle center, and the bubble centerline have been used to characterize bubble burst locations [16]. After nucleating a hole on the cap, a bubble will roll up. The roll-up velocity was first used to calculate the thickness of soap film [22], and it was widely used to solve for bubble cap film thickness [1, 6, 19]. Some people have used laser interference to measure the thickness of the top of a cap film and to use it to characterize the thickness of a liquid cap. Ke et al. [23] used a Microspot Film Thickness measurement system (MFS) to measure thickness. The cap film thickness was measured with white light interference technology to study the effect of surfactants on the bubble drainage and rupturing [17]. High-resolution images were also used to measure the thickness of the bubble cap [12].

The research about the bubble bursting characteristics on a free surface has mainly focused on a single variable.
The influence of the bubble lifetime mostly affects the impact of the bubble radii. The influence of the gas and liquid temperatures and the working fluid is not yet clear, especially in terms of the corresponding relationship between the bubble lifetime and the cap film thickness for different conditions. Almost all of the studies have been based on pure water, so the applications and effects of the bubble rupture characteristics of a liquid containing aerosol need to be verified. In liquid-phase working fluids where surface tension is difficult to measure, the application of the film roll-up velocity to characterize bubble behavior needs further research.

In this research, experimental methods were used to study the rupture and drainage characteristics of bubbles on a free surface. High-speed photography was used to collect the bubble rupture process. Cameras were used to capture the lifetime of the bubbles and to correspond to bubble bursting behavior. First, the bubble burst measuring experiment was conducted in deionized water. The experiment conditions were changed (bubble radius, liquid temperature, and air temperature) to measure and calculate the bubble lifetime, cap film roll-up velocity, and cap thickness. Subsequently, aerosol particles were added to the bulk to explore its influence on the experimental results.

\section{Experimental Device and Methods}

2.1. Experimental Device. The experimental setup is shown in Figure 1. The experiment consisted of three parts. (1) The preparation and transportation of aerosol suspension: this part mainly achieves the dispersion of aerosol particles and uniform distribution in the liquid. (2) The heating part of the aerosol suspension: this part was mainly used for heating the aerosol suspensions. To prevent subcooled boiling and to reduce aerosol diffusiophoresis, thermophoresis, and agglomeration caused by direct heating, copper tubes were selected and designed to be used in coils. (3) The main experimental section: this part was mainly composed of aerosol-containing bubbles that floated and ruptured on the liquid surface. Highspeed photography and cameras were used to collect the process.

Before the experiment, the experimental circuit was cleaned with deionized water. The dried aerosol was selected to prepare for aerosol suspension and to obtain a certain concentration. A proportional-integral-derivative (PID) temperature control system was used to control the temperature. Thermocouples were used to measure the liquid temperature (installed in the overflow tank) and the air temperature (installed $2 \mathrm{~cm}$ above the overflow tank). The air compressor and the dryer were turned on, and single bubbles were generated by bubbling the orifice plate. Highspeed photography was installed with lenses and cameras, a light source and a homogenizing plate were placed at the rear of the visualization window, and parameters such as the resolution and exposure time were adjusted to enable the high-speed photography to clearly capture the rupture process of the bubbles. 


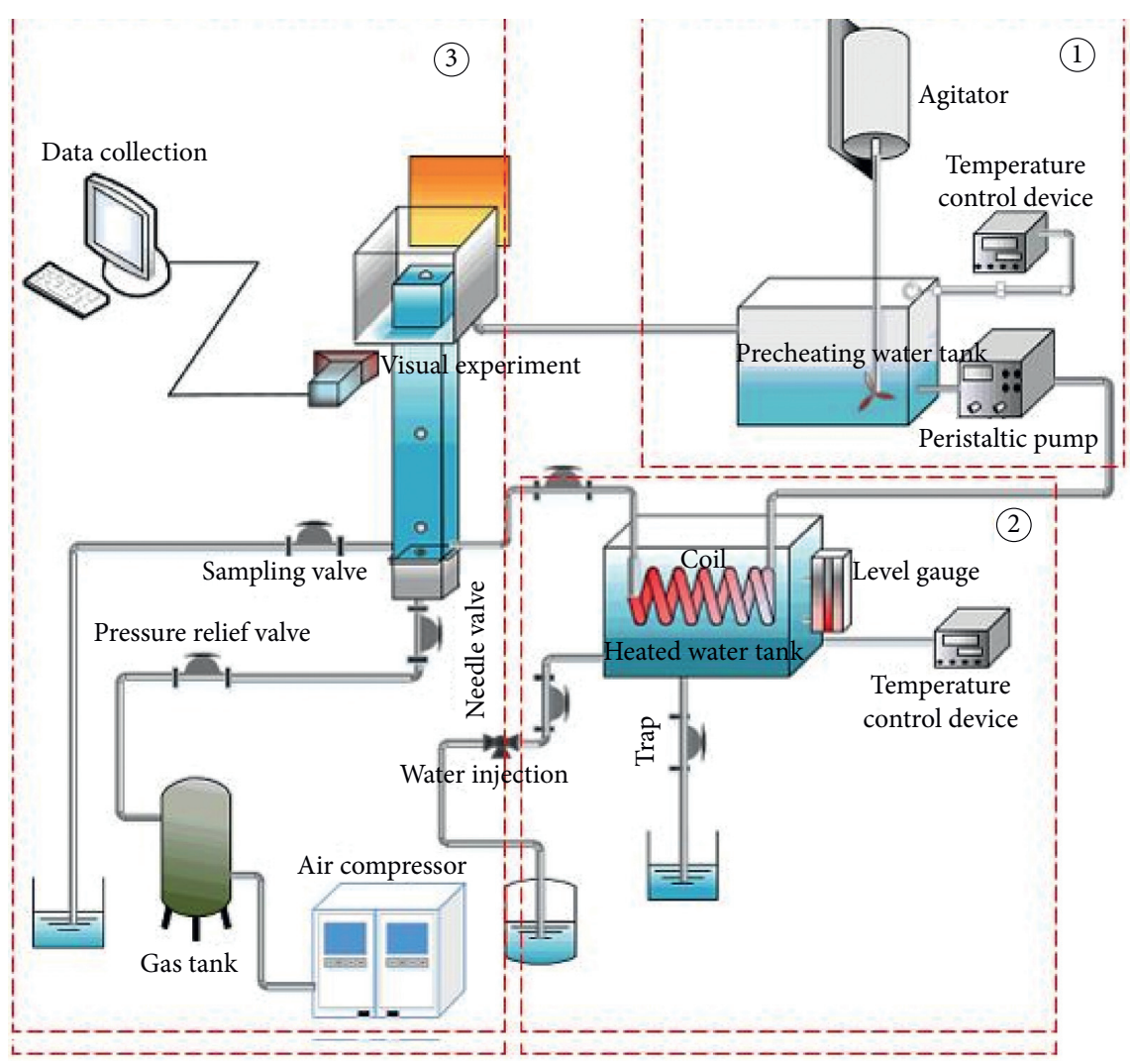

FIGURE 1: Schematic diagram of experimental system.

2.2. Data Processing Method. A Phantom V641 high-speed photography camera combined with a $105 \mathrm{~mm} \mathrm{f/2.8 \textrm {G }}$ Nikon macro lens was used to capture the complete bubble burst process. To obtain the required parameters of the bubbles and droplets, a series of image processing steps needed to be performed on the captured visualization images.

As shown in Figure 2, the diameter of the cap film in this research was calculated based on the distance between the two points on the video image of the bubble edge, i.e., $R_{f}$. The bubble diameter was determined to be the diameter of a circle that coincided with the liquid cap by taking multiple data points on the bubble cap film, i.e., $R_{b}$.

High-speed photography was used to gather the rupture process. The resolution was $1280 \times 500(24 \mu \mathrm{m} /$ pixel $)$ and the sampling frequency was 7000 frames. The film rolled up after nucleating a hole in the cap. The visualized image is shown in Figure 3. The visualized image of the bubble bursting was intercepted. Then the coordinates of the corresponding positions of the arrows in each picture were determined with the help of image processing software. The distance moved by the liquid film ring of the two frames is obtained using the correspondence to the fitted spherical equation of the bubble. The results of 10 frames were averaged and divided by frame difference so that the average cap film receding velocity of the bubbles could be obtained.

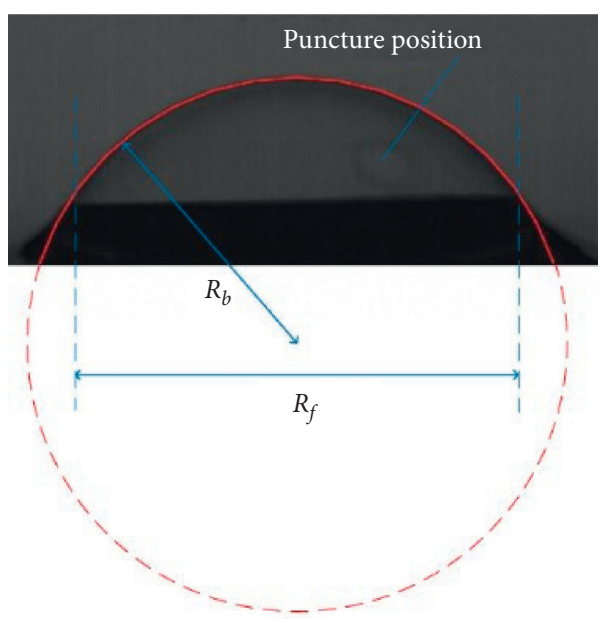

FIgURE 2: Definition of bubble cap film diameter and bubble diameter.

We used the camera to obtain the bubble lifetime. The sampling frequency was $50 \mathrm{~Hz}$. We selected the time of a bubble rising to the free surface as the initial time and the time of a bubble disappearing or rupturing, as viewed in the camera, as the final time. The calculated time difference was the bubble lifetime. Nearly 400 bubble lifetimes were surveyed for each condition. The one-to-one correspondence between the bubble lifetime and the bubble rupture process was made by sounding a signal. 

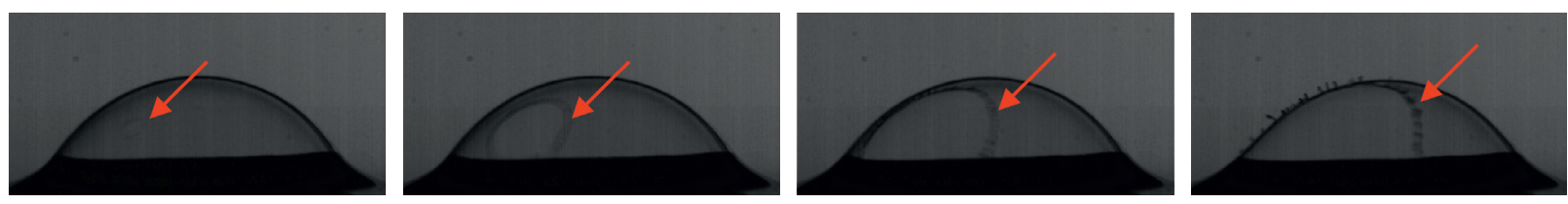

FiguRe 3: Visualized image of bubble cap film roll-up.

\section{Results and Discussion}

3.1. Bubble Burst Characteristics. Previous studies have shown that the Bo number can be used to characterize bubbles floating to a liquid surface. When bubble cap film radius was in the range of $4-6 \mathrm{~mm}$ [1], the bubble could generate film droplets, and the droplet sizes could be used for the visualization while neglecting the effect of gravity drainage. In this research, the bubble radius $R$ was in the range of 6-7 mm, and the liquid film drainage was mainly driven by surface tension. The droplets generated by the bubble burst could meet the requirements of visualization and the conditions of the empirical relationship used.

Figure 4 shows the images of two typical bubble bursts with the puncture positions at the top and bottom. It could be found from the figure that the puncture position generated at the top of the bubble generally generated fewer droplets, and their velocities were mostly downward. In contrast, the puncture position at the bottom of the bubble usually generated more droplets, with velocities in all directions.

The dimensionless radial distance $r_{i}=2 X_{i} / D_{i}\left(X_{i}\right.$ represents the horizontal length of the rupture point to the edge of the cap to cap film radius; $D_{i}$ is the bubble cap diameter) was used to evaluate the puncture position of the bubbles. For radial dimensionless length partitions, the dimensionless radial length in the interval $(0,0.2)$ was characterized by top rupture; the location at $(0.8,1)$ was characterized by the bottom rupture. Figure 5 shows nearly 200 bubbles rupture positions for the liquid temperature of $19^{\circ} \mathrm{C}$, the air temperature of $20^{\circ} \mathrm{C}$, and deionized water. The 200 bubbles rupture initiation points close to the radius of the liquid surface bubble were measured.

From Figure 5, it could be found that the probability that the dimensionless radial distance between $(0.8,1)$ was $64.55 \%$ and the probability between $(0,0.2)$ was $7.41 \%$. The dimensionless radial distance $r>0.4$ was $81.57 \%$, and the probability of the bubble bursting at the bottom was large, so most of the bubbles burst at the bottom or the middle.

In this research, the location of the rupture was no longer the main object of investigation, so the measured cap film roll-up velocity and thickness were selected for bubbles with close dimensionless radial distances. Bubbles with nearrupture (bottom or middle rupture) locations were selected.

3.2. Bubble Lifetime. The visualization of the bubble bursts for different bubble lifetimes is shown in Figure 6. Obviously, the lifetime affected the bubble rupture process. As the lifetime of the bubble increased, the bubble cap film thickness at rupture decreased and the number of generated droplets increased.
Figure 7 (a) shows a histogram of the bubble lifetime distribution with a liquid temperature of $19.0^{\circ} \mathrm{C}$, air temperature of $20.0^{\circ} \mathrm{C}$, and deionized water. The lifetime span was $(0,14)$ and the interval center was 0.5 . PDF $\left(t_{b}\right)$ represents the probability density function. To explore the effect of the bubble radius on the bubble lifetime, the gas volume was adjusted. The bubble cap film diameters were in the ranges of $11-12 \mathrm{~mm}$ and $12.4-13.6 \mathrm{~mm}$.

It could be found from Figure 8 that the bubble lifetime distribution for different conditions approximately obeyed the normal distribution. We calculated the average lifetimes described above. The results were $4.599 \mathrm{~s}$ and $4.170 \mathrm{~s}$. The heater was turned on to increase the liquid temperature to $47.5^{\circ} \mathrm{C}$, and the corresponding air temperature was $23.9^{\circ} \mathrm{C}$. We also measured the lifetimes of the large and small bubbles. The results are shown in Figure 8. The average values of the measured lifetime distribution of the small and large bubbles were $6.724 \mathrm{~s}$ and $5.780 \mathrm{~s}$. As bubble radius increased, the lifetime of the bubble decreased.

We used the bubble lifetime divided by the average lifetime, namely, for normalized bubble lifetimes, to reflect the lifetime distribution of the bubbles more intuitively. Additionally, we explored the applicable fitting formulas. According to the calculation formulas for different conditions proposed by predecessors, the scope of application was expanded by adding fitting parameters; that is, it could be applied to the calculation of various gas and liquid temperatures. The calculation formula of Zheng's normalized bubble lifetime distribution [14] was applicable to different bubble radii and different types of solutions. According to this form, the fitting parameter $b$ was added to calculate the normalized lifetime distribution at different temperatures, i.e., formula (1). Poulain's formula for a normalized lifetime distribution [1] was also used to calculate the consequences. We also used parameter $c$ to modify the distribution, i.e., formula (2). Both formulas are given by

$$
\begin{aligned}
y & =\frac{x}{a^{2} \cdot e^{-\left(x^{2} /\left(2 a^{2}\right)+b\right)},} \\
f(x) & =0.307 x^{1 / 3} \exp \left(-0.92 x^{4 / 3}+c\right)
\end{aligned}
$$

Figure 9 shows the results of the normalized bubble lifetime distribution and the fitting curves. The liquid temperatures were further increased to $60.0^{\circ} \mathrm{C}$ and $71.5^{\circ} \mathrm{C}$. Additionally, the average lifetimes were calculated and then fitted using formulas (1) and (2). The results are shown in Table 1. Except for a certain working condition, the fitting degree of the two formulas was more than $50 \%$. Hence, the revised model could be used to predict the normalized lifetimes at different temperatures. 

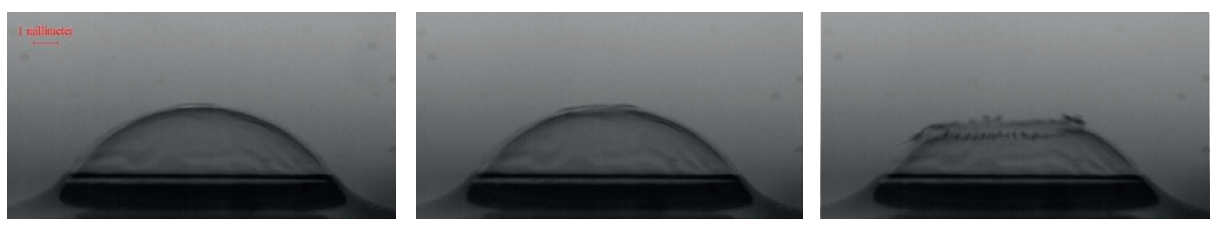

(a)
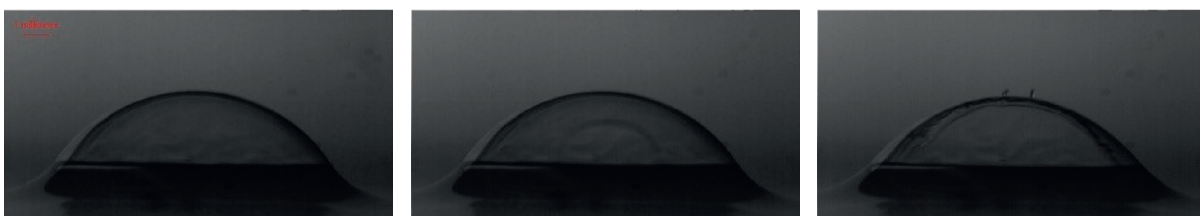

(b)
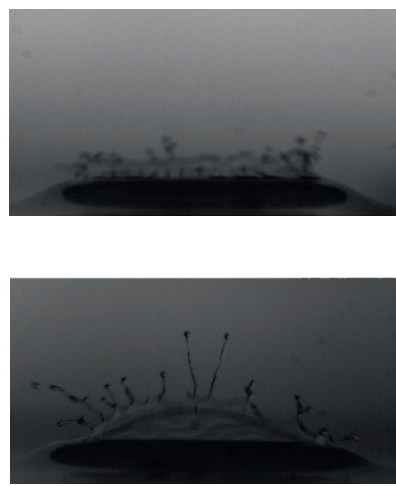

FIGURE 4: Visualization of bubbles bursting at different locations: (a) top and (b) bottom.

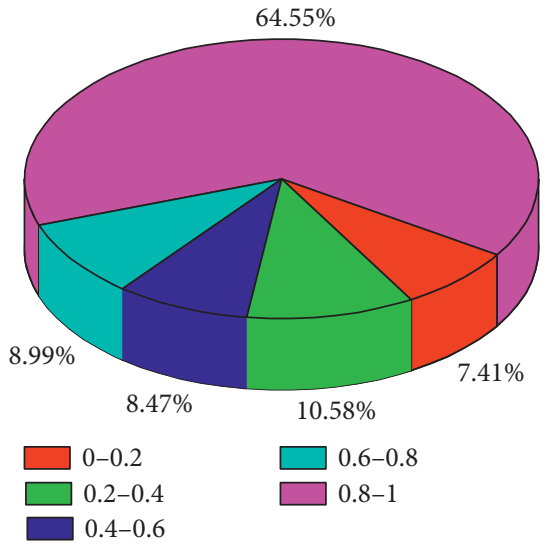

Figure 5: Dimensionless radial length distribution.

To describe the effect of the air temperature qualitatively, at the liquid temperature of $60.0^{\circ} \mathrm{C}$, a method for adding a lid to the top of the box was used to change the temperature of the air from $30.0^{\circ} \mathrm{C}$ to $51.5^{\circ} \mathrm{C}$. After the temperature rose to a certain degree, as the air temperature increased, the bubble lifetime tended to decrease. The measured velocity of the particles on the cap film could also verify this behavior. The speed was $0.017 \mathrm{~m} / \mathrm{s}$ at $30.0^{\circ} \mathrm{C}$ and $0.024 \mathrm{~m} / \mathrm{s}$ at $51.5^{\circ} \mathrm{C}$ (the calculation methods and the results are introduced below). That is, the higher the air temperature was, the faster the liquid film drainage rate was, the thinner the film was, the more likely the bubbles were to rupture, and the shorter the lifetimes of the bubble were.

Figure 10 is a schematic diagram of the bubble drainage characteristics on the free surface. For gravity drainage, the direction was down the cap film. When $T_{\text {liquid }}=60.0^{\circ} \mathrm{C}$ and $T_{\text {air }}=30.0^{\circ} \mathrm{C}$, the cap cooled, as shown in Figure 10 . Therefore, for the case of $T_{\text {cap }}<T_{w}$, due to the Marangoni effect, there was a driving force opposite to the gravity drainage. When the temperature of the liquid was constant and the temperature of the air increased, the cooling of $T_{\text {cap }}$ weakened. Hence, the temperature difference between the cap film and the bulk water decreased; that is, the film drainage rate increased and the bubble lifetime decreased.
Table 1 shows the results of the fitting experimental values according to the formulas of Zheng and Poulain. In general, Poulain's formula fits well, and the degree of fit was mostly above $60 \%$, while Zheng's formula was better when the liquid temperature was higher (above $60^{\circ} \mathrm{C}$ ), generally more than $75 \%$.

After adding aerosol particles to the bulk, the lifetime distribution of the bubbles at different liquid temperatures was measured for the $\mathrm{TiO}_{2}$ aerosol suspension with a concentration of $0.05 \mathrm{~g} / \mathrm{L}$. To explore the effect of the liquid working medium on the lifetime of the bubble, the radius of the bubble was similar to that of deionized water. The selected temperatures were $27.6^{\circ} \mathrm{C}, 48.7^{\circ} \mathrm{C}$, and $70.3^{\circ} \mathrm{C}$. The different fitting results are shown in Table 2.

It could be clearly found from Table 2 that the bubble lifetime distribution of the aerosol-containing liquid surface had a good fitting effect using Zheng's formula, and the fitting degrees were all above $80 \%$. While using the formula of Poulain, the fitting effect was general.

The average lifetime distribution could also reflect the features. Figure 11 shows the results of the average lifetime distribution of the bubbles on the surface of the liquid phase of the deionized water and the $0.05 \mathrm{~g} / \mathrm{L} \mathrm{TiO}_{2}$ aerosol suspension. The results of the average lifetime distribution were similar. With the increase of the liquid temperature, the lifetime of the bubble first increased and then decreased. The $0.05 \mathrm{~g} / \mathrm{L} \mathrm{TiO}{ }_{2}$ aerosol suspension liquid surface bubble average lifetime was significantly longer than that of deionized water for the same conditions.

After generating from the bottom of the bulk, bubbles rose to the free surface of the liquid. When the aerosol was contained in the liquid phase, the aerosol entered the bubble cap film along with the drainage. For the aerosol generated during the bubble generation process and the gas-liquid exchange, the entire cap film was filled with particles.

When the liquid phase contained aerosols, the bubbles rose to the free surface. The aerosol was enriched on the top of the cap during drainage and it induced an aerosol concentration gradient. According to previous studies, the higher the aerosol concentration was, the greater the surface tension was. Therefore, the surface 

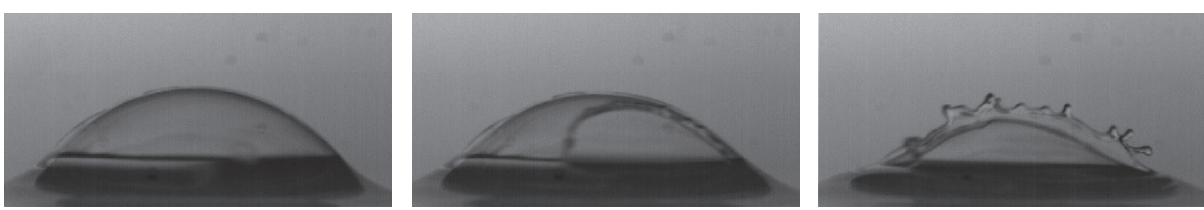

(a)
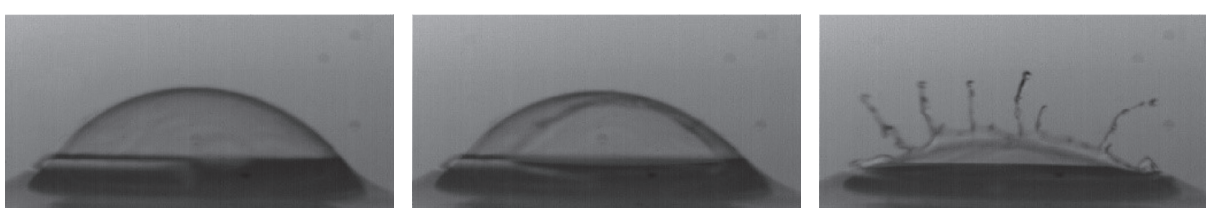

(b)
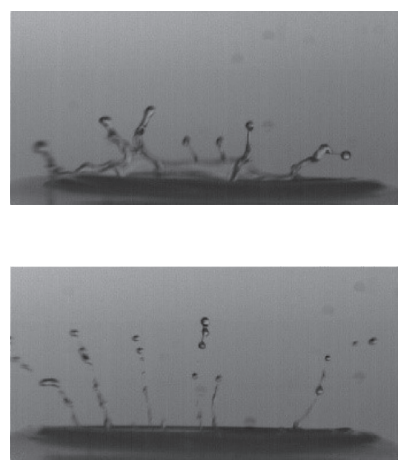

Figure 6: Visualization of bubble bursting with different lifetimes: (a) $T=0.32 \mathrm{~s}$ and (b) $T=5.76 \mathrm{~s}$.

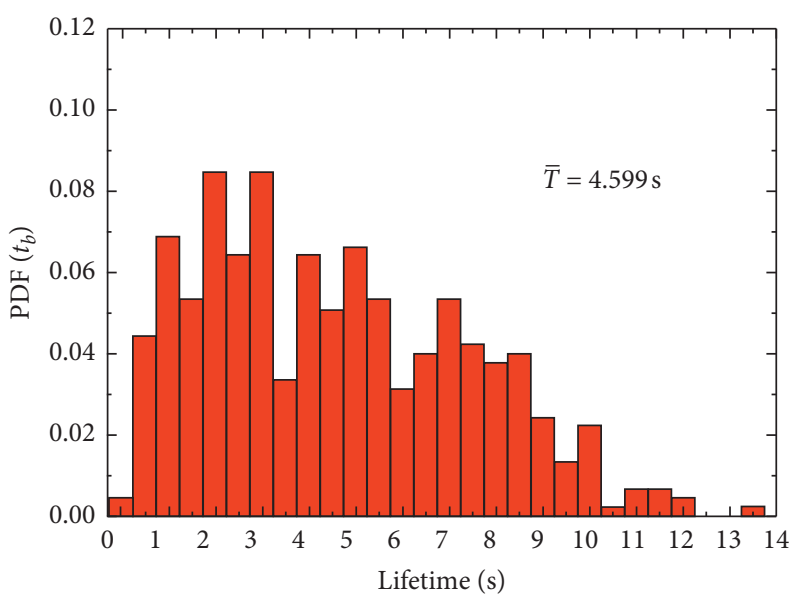

(a)

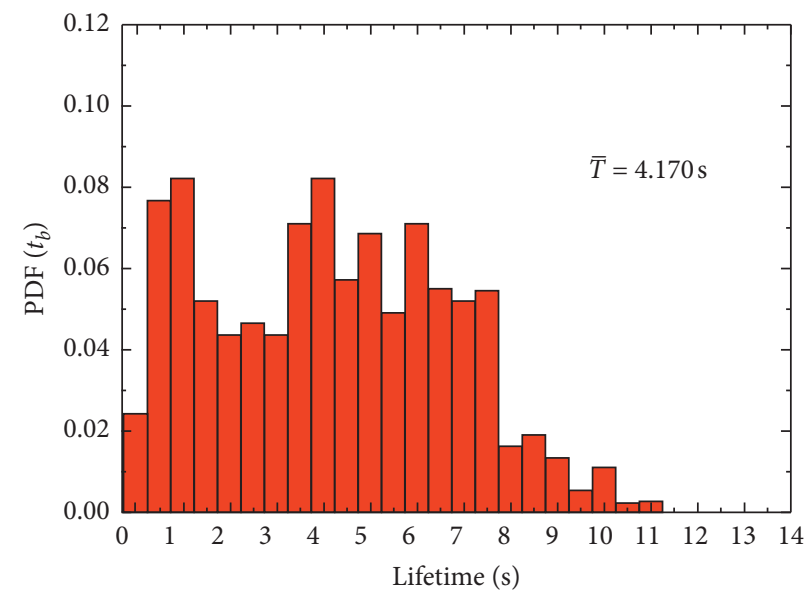

(b)

Figure 7: Bubble lifetime distribution histogram at a liquid temperature of $19.0^{\circ} \mathrm{C}$ and an air temperature of $20.0^{\circ} \mathrm{C}$ : (a) cap diameter $=11$ $12 \mathrm{~mm}$ and (b) cap diameter $=12.4-13.6 \mathrm{~mm}$.

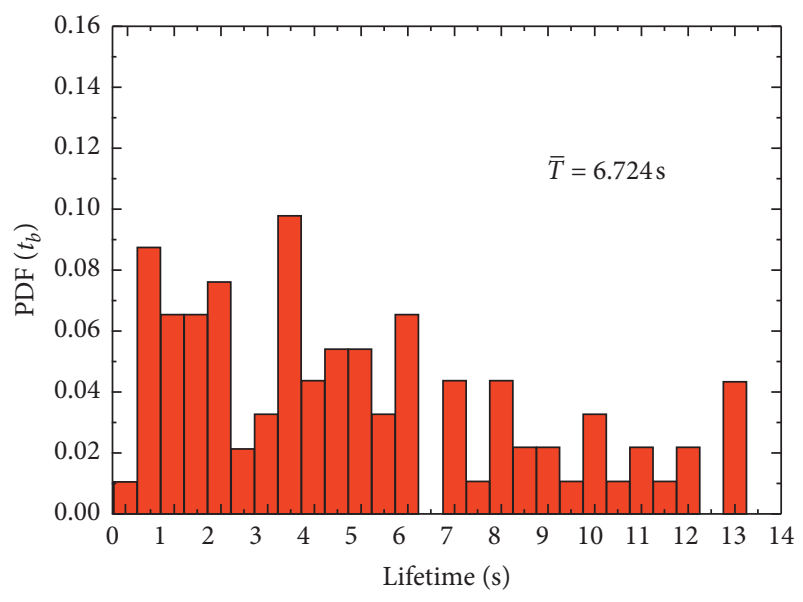

(a)

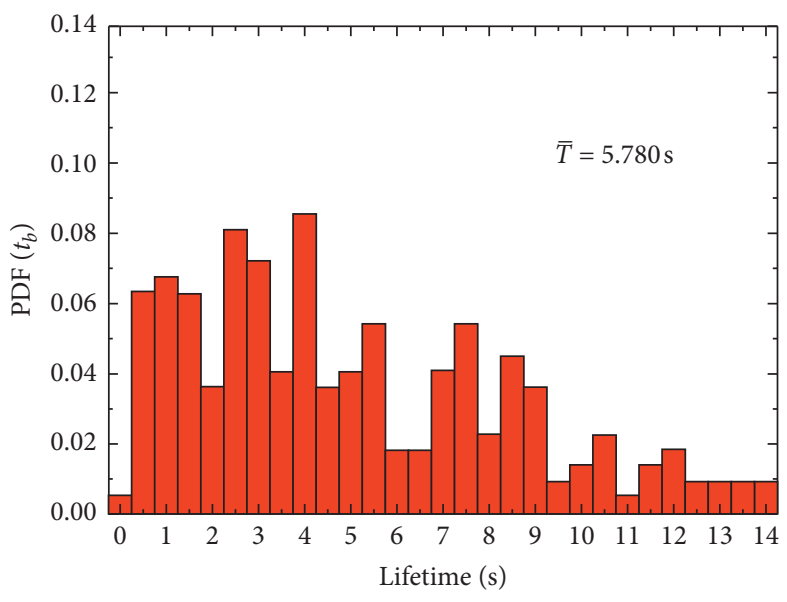

(b)

Figure 8: Bubble lifetime distribution histogram at a liquid temperature of $47.5^{\circ} \mathrm{C}$ and an air temperature of $23.9^{\circ} \mathrm{C}$ : $(\mathrm{a})$ cap diameter $=9.4-10.2 \mathrm{~mm}$ and $(\mathrm{b})$ cap diameter $=12.4-13.2 \mathrm{~mm}$. 


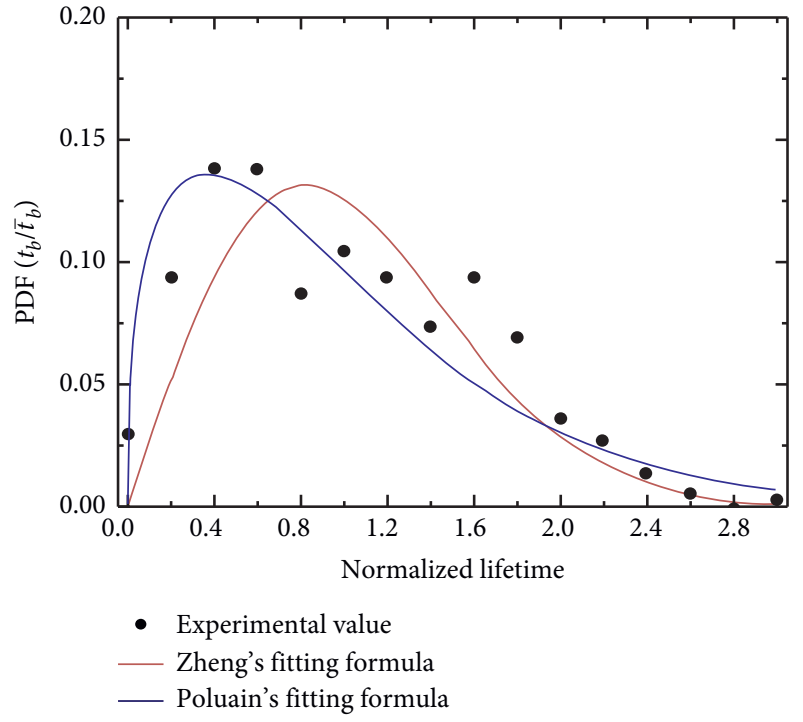

(a)

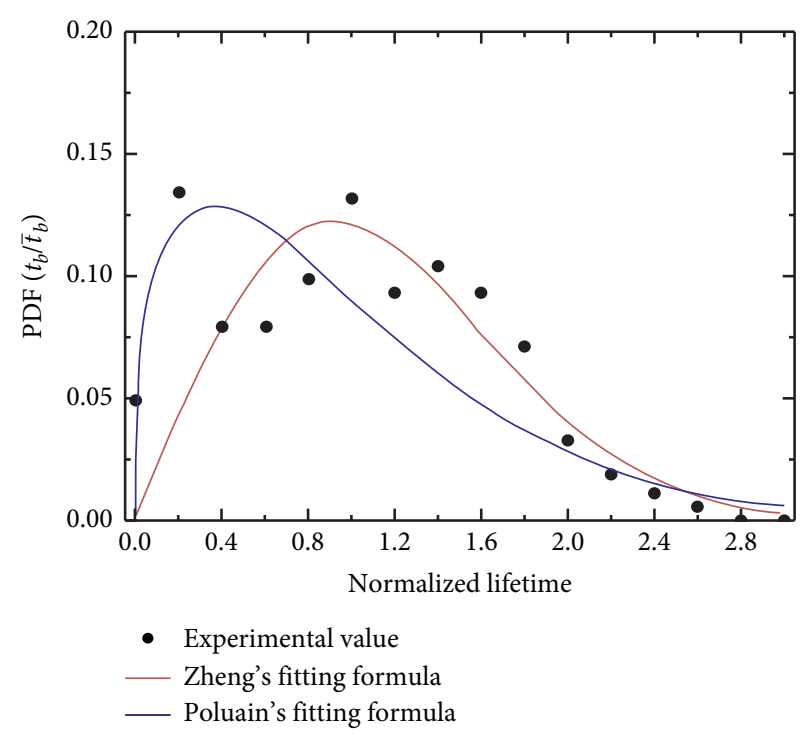

(b)

FIGURE 9: Normalized bubble lifetime distribution and fitting curves: (a) cap diameter =11-12 mm and (b) cap diameter = 12.4-13.6 mm.

TABLE 1: Fitting results of bubble lifetime distribution on the surface of ionic water for different conditions.

\begin{tabular}{|c|c|c|c|c|c|c|}
\hline Temperature $\left({ }^{\circ} \mathrm{C}\right)$ & Bubble radius $(\mathrm{mm})$ & Average lifetime (s) & Fitting parameters $a, b[14]$ & Fitness & Fitting parameter $c[1]$ & Fitness \\
\hline \multirow{2}{*}{$\begin{array}{l}\text { Liquid, } 19.0 \\
\text { Air, } 20.0\end{array}$} & $5.5-6.0$ & 4.599 & $\begin{array}{l}1.20928 \\
0.95827\end{array}$ & 69.437 & -0.23868 & 81.744 \\
\hline & $6.2-6.8$ & 4.170 & $\begin{array}{l}1.09271 \\
1.34195\end{array}$ & 56.051 & -0.29276 & 56.077 \\
\hline \multirow{2}{*}{$\begin{array}{l}\text { Liquid, } 47.5 \\
\text { Air, } 23.9\end{array}$} & $4.7-5.1$ & 6.724 & $\begin{array}{c}1.89178 \\
-0.53596\end{array}$ & 30.533 & -0.28026 & 57.814 \\
\hline & $6.2-6.6$ & 5.780 & $\begin{array}{c}1.65126 \\
-0.15189 \\
\end{array}$ & 58.719 & -0.16473 & 93.538 \\
\hline $\begin{array}{l}\text { Liquid, } 60.0 \\
\text { Air, } 30.0\end{array}$ & $6.2-6.4$ & 4.040 & $\begin{array}{l}1.22175 \\
0.9324\end{array}$ & 74.355 & -0.29311 & 61.805 \\
\hline Liquid, 60.0 Air, 51.5 & $6.2-6.8$ & 3.063 & $\begin{array}{l}1.17257 \\
0.97578 \\
\end{array}$ & 92.322 & -0.22822 & 66.036 \\
\hline
\end{tabular}

tension gradient on the cap film introduced a Marangoni driving force in the upward direction, which delayed the cap drainage velocity of the bubble. When the bursting characteristics of bubbles were not considered, the addition of aerosol increased the lifetime of the bubbles.

\subsection{Liquid Film Roll-Up Velocity and Liquid Cap Thickness}

3.3.1. Film Roll-Up Velocity and Cap Film Thickness in Deionized Water. The obtained liquid film roll-up velocity measurement was mainly used to calculate the cap film thickness. Previous empirical equations proved that the film opening velocity was related to the radius of the bubble $[19,24]$. Because the bubble radius in this research was no longer the main research variable, the bubble radius was selected in the experiment; $\pm \Delta R \leq 0.5 \mathrm{~mm}$ was very close, indicating that they have similar puncture characteristics. It could be considered that the bubble had similar burst characteristics.
The opening speed of the deionized water was measured as well as the correspondence to the lifetime of the bubble. Figure 12 shows the results at a liquid temperature of $19.0^{\circ} \mathrm{C}$ and an air temperature of $20.0^{\circ} \mathrm{C}$. The relationship between the bubble cap film thickness and the lifetime was generally used to characterize the bubble burst process, and the inverse relationship between the liquid cap roll-up velocity and the cap thickness made us consider using the liquid film curling rate to calculate the bubble life. In terms of the use of the liquid film curling rate to characterize the bursting characteristics of bubbles, the following formula seemed to have more application value:

$$
v=c \cdot t^{1 / 3}
$$

The data were fitted with formula (3). The fitting parameter was $c=3.414$ and the degree of fitting was $80.664 \%$. To reflect the trait of fitting more intuitively, a logarithmic coordinate system was established and the fitting curve was 


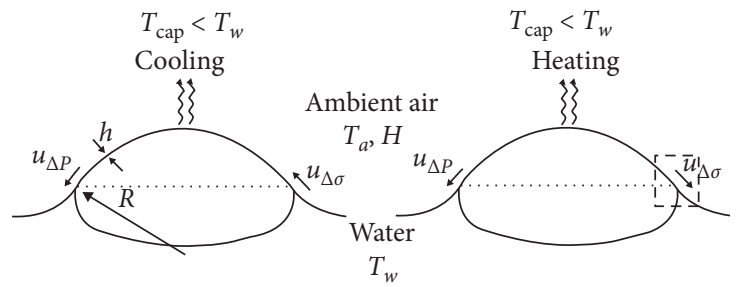

Figure 10: Marangoni effect of bubble drainage diagram [1].

TABLE 2: Fitting results of bubble lifetime distribution of $0.05 \mathrm{~g} / \mathrm{L} \mathrm{TiO}_{2}$ aerosol suspension for different conditions.

\begin{tabular}{lcccccc}
\hline Temperature $\left({ }^{\circ} \mathrm{C}\right)$ & Bubble radius $(\mathrm{mm})$ & Average lifetime $(\mathrm{s})$ & Fitting parameters $a, b[14]$ & Fitness & Fitting parameter $c[1]$ & Fitness $(\%)$ \\
\hline $\begin{array}{l}\text { Liquid, 27.6 } \\
\text { Air, 23.1 }\end{array}$ & $6.6-7.0$ & 7.295 & 1.138821 .10449 & 81.783 & -0.31652 & 47.815 \\
\hline $\begin{array}{l}\text { Liquid, } 47.5 \\
\text { Air, 23.9 }\end{array}$ & $6.6-7.2$ & 13.458 & 1.334370 .56016 & 81.989 & -0.22682 & 71.231 \\
\hline $\begin{array}{l}\text { Liquid, 71.5 } \\
\text { Air, 33.2 }\end{array}$ & $6.2-6.8$ & 8.928 & $\begin{array}{l}1.24692 \\
0.39721\end{array}$ & 85.188 & 0.12776 & 62.262 \\
\hline
\end{tabular}

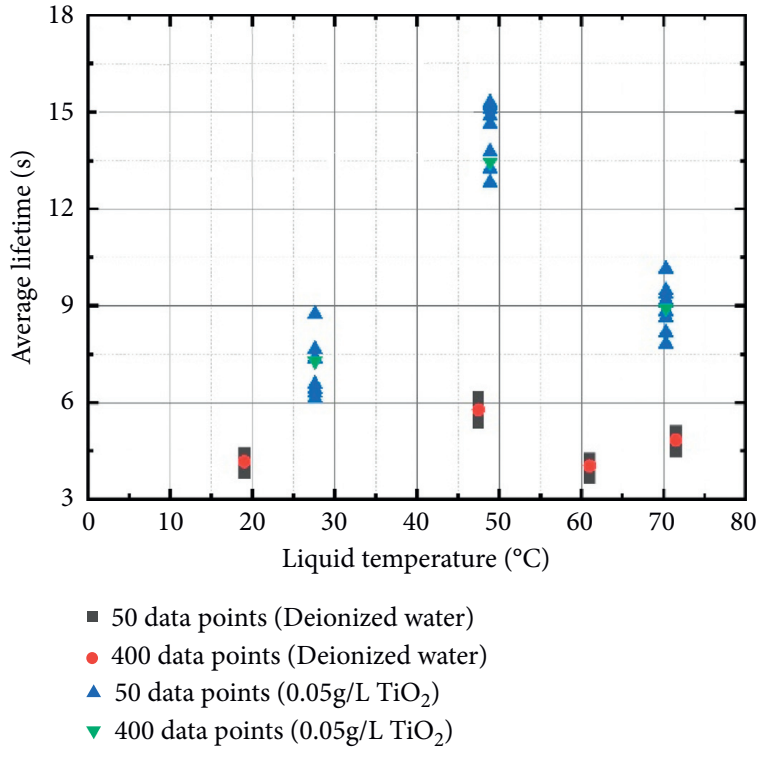

Figure 11: Bubble average lifetime measurement results.

drawn, as shown in Figure 12(b). The dotted line in the figure indicates the fitting error. The results demonstrated that the deviation of the fitting curve was within the range of $-15 \%$ to $+25 \%$. It could be found from the figure that the roll-up velocity of the cap film and the bubble lifetime obeyed an exponential rule.

The bubble cap film thicknesses at rupture were calculated with the speed and fit data points according to the following formula. The result is shown in Figure 13:

$$
h=d \cdot t^{-2 / 3} \text {. }
$$

The obtained fitting parameter was $d=10.020$ and the fitting degree was $75.504 \%$. The graph was shifted to logarithmic coordinates and the error bars were provided. The results are displayed in Figure 13(b). Obviously, the exponential law of the bubble cap film thickness and the lifetime was consistent with the law of the roll-up velocity.

Similarly, the thicknesses of the bubble cap for different conditions were measured at different liquid temperatures. Because the gas above the bubbles was exposed during the experiment, the increase of the liquid temperature inevitably heated the air above the bubble, but compared to the change of the liquid temperature, the effect of the air temperature can be ignored. Figure 14 shows the corresponding relationship at different liquid temperatures. It could be determined from Figure 14 that the bubble cap film thickness and the lifetimes of the bubbles at different liquid temperatures obeyed an exponential change law, and as the liquid temperature increased, the lifetimes of the bubbles show an increasing trend.

The results for fitting the cap film thickness for different working conditions are shown in Figure 15. It could be clearly found from the figure that as the liquid temperature increased, the fitting curve shifted upward, and the fitting parameters could reflect the change. The fitting parameter $d$ increased from 10.052 to 11.714 until it reached 13.916 .

The previous calculation formula of the liquid discharge rate could be used to characterize the corresponding relationship between the cap film thickness and the bubble lifetime. The drainage rate was directly determined by the surface tension. As the temperature of the liquid increased, the surface tension decreased, the cap film drainage speed slowed down, and the cap film thickness at rupture thickened. 


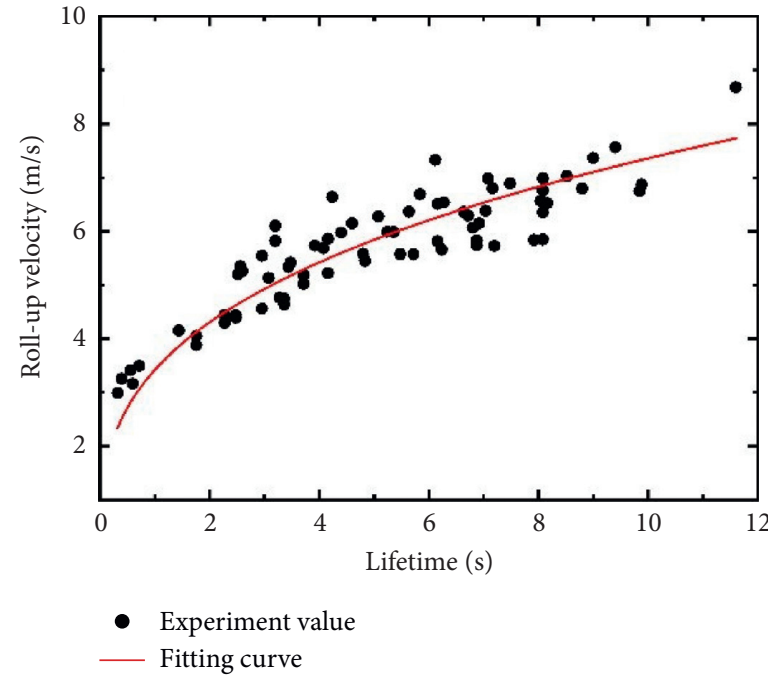

(a)

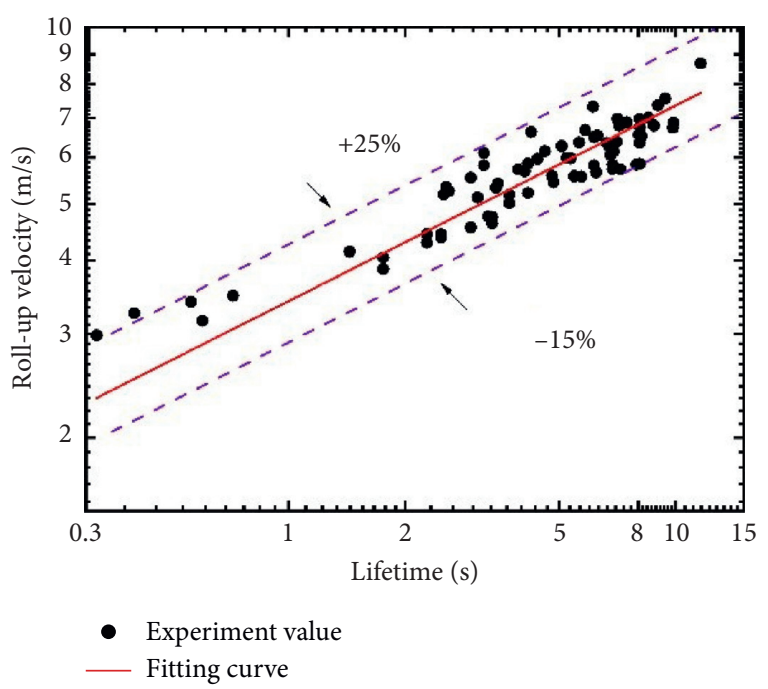

(b)

FIgURE 12: Correspondence of the film roll-up velocity and the bubble lifetime: (a) curve fitting and (b) error analysis.

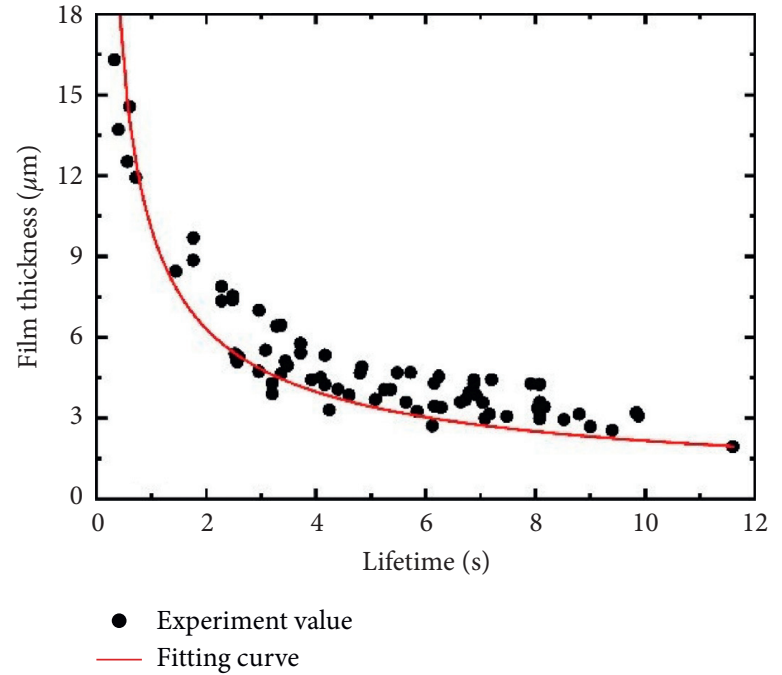

(a)

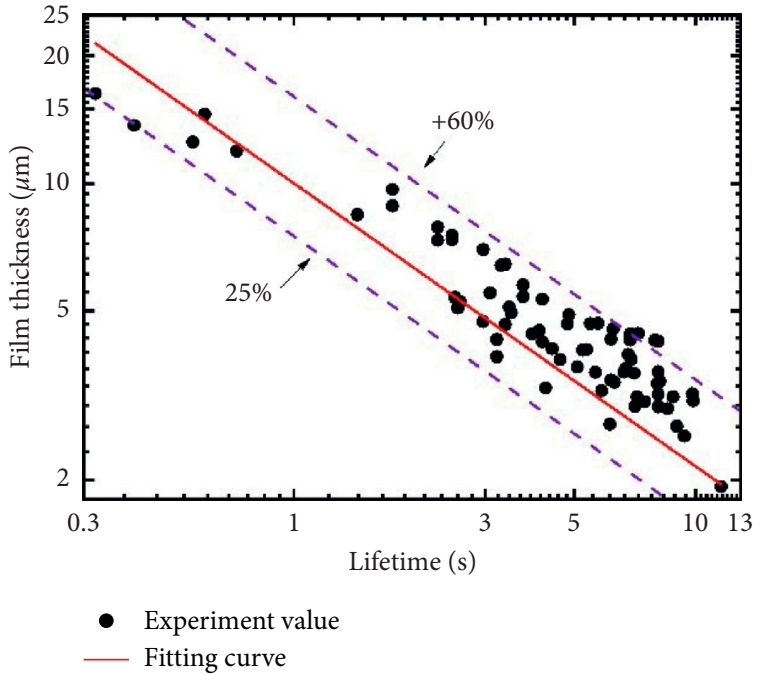

(b)

FIgURE 13: Correspondence of cap film thickness and bubble lifetime: (a) curve fitting and (b) error analysis.

The effect of the gas phase temperature on the liquid discharge characteristics and the liquid cap thickness was investigated. Figure 16 shows the corresponding relationship between the bubble cap film thickness and time and the fitting curve at a liquid temperature of $60.0^{\circ} \mathrm{C}$. It could be seen from Figure 16 that when the liquid temperature remained stable, as the gas-phase temperature increased, the cap film thickness showed a decreasing trend. It could also be seen from the fitted curve of (b) that as the gas phase temperature increased from $30.0^{\circ} \mathrm{C}$ to $51.5^{\circ} \mathrm{C}$, the fitted curve moved downward and the fitted parameter $d$ decreased from 13.940 to 13.143 .

This behavior could be illustrated by the Marangoni effect diagram in Figure 10. The liquid temperature was greater than the air temperature, so the cap cooled. When the air temperature was approximately constant and the liquid temperature rose, the cooling rate was larger, the cap drainage speed of the bubble with the same lifetime slowed down, and the cap film thickness at rupture increased. The change of the air temperature changed the drainage characteristics of the bubble. For the specific working conditions in this research, the increase of the air temperature weakened the Marangoni force, thereby increasing the drainage rate.

To verify the idea, the speed of movement of the particles on the bubble cap was measured. The visualized images of the bubbles on the liquid surface for different liquid temperature conditions were selected. The red circle in the measurement figure shows the position of the particles. 


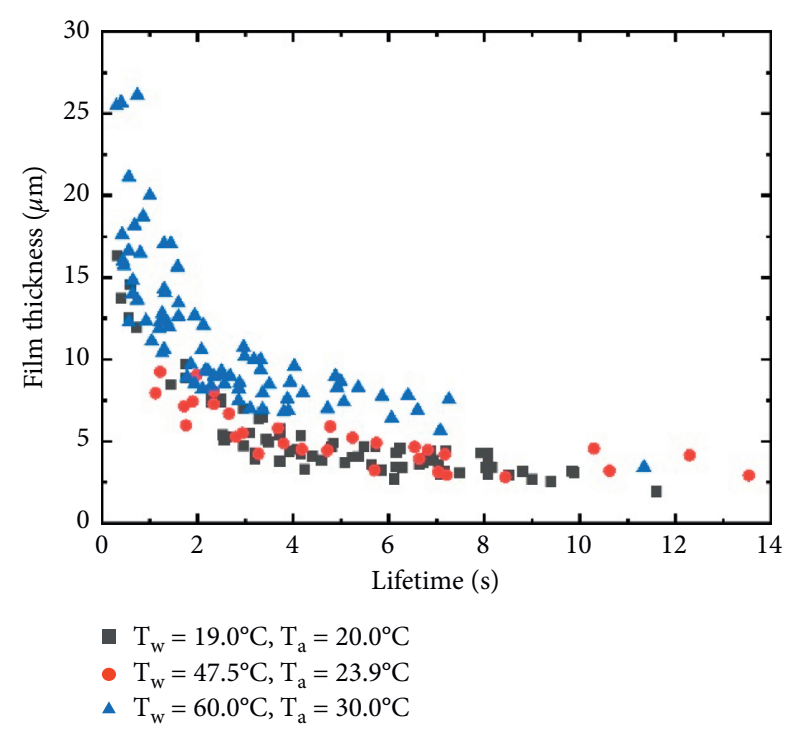

Figure 14: Correspondence of cap film thicknesses and bubble lifetimes at different liquid temperature.

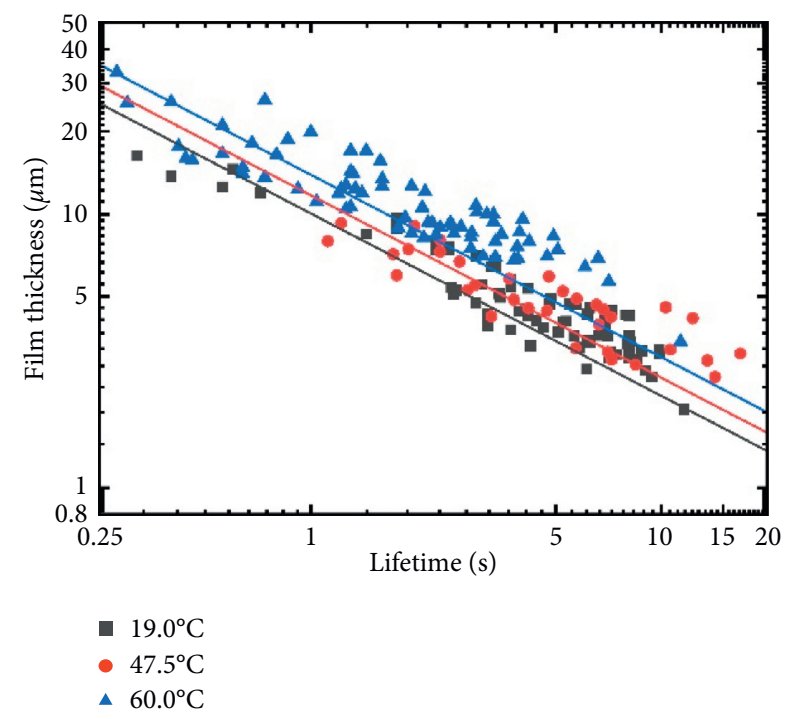

FIgure 15: Curve fitting at different liquid temperatures.

Figure 17 shows the visualizing images. The calculated values for different liquid temperatures were $V_{19.0}=0.5 \mathrm{~m} / \mathrm{s}$, $V_{47.6}=0.017 \mathrm{~m} / \mathrm{s}$, and $V_{60.0}=0.27 \mathrm{~m} / \mathrm{s}$. As the temperature of the liquid increased, the cap film drainage speed slowed down and cap film thickness at rupture thickened. The velocity of the particles was measured when the air temperatures were $30.0^{\circ} \mathrm{C}$ and $51.5^{\circ} \mathrm{C}$ at liquid temperature of $60.0^{\circ} \mathrm{C}$. The results were $V_{30.0}=0.017 \mathrm{~m} / \mathrm{s}$ and $V_{51.5}=0.024 \mathrm{~m} / \mathrm{s}$. As the temperature of the air increased, the cap film drainage speed slowed down and the cap film thickness at rupture thinned.

3.3.2. Film Roll-Up Velocity in Aerosol Suspension. To investigate the effect of aerosols on the bubble burst characteristics, aerosol was added to the liquid, and parameters

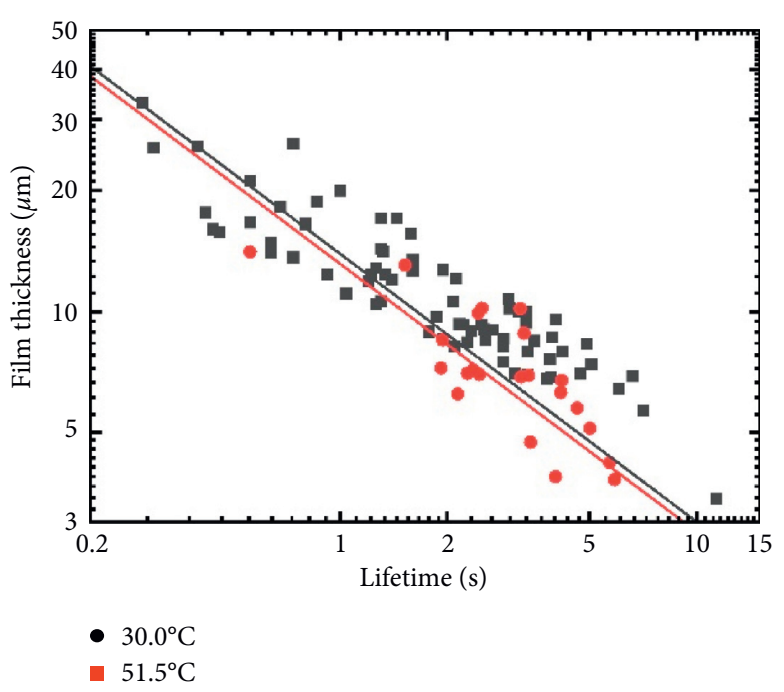

FIgURE 16: Correspondence of the bubble cap film thickness lifetime at different gas-phase temperatures.

such as the liquid film opening speed were measured. Figure 18 shows the measurement results of the aerosol suspension at a mass concentration of $0.05 \mathrm{~g} / \mathrm{L}$ at the liquid temperature of $27.6^{\circ} \mathrm{C}$ and the air temperature of $26.1^{\circ} \mathrm{C}$. Formula (3) was used for fitting. The fitting result is shown in Figure 18(b).

Similar to the experimental conditions of deionized water, when the aerosol was contained in the liquid, the bubble opening receded with isotropic speed and the bubble lifetime showed an exponential change. The error of the curve was within $\pm 20 \%$. The liquid temperatures were raised to $54.9^{\circ} \mathrm{C}$ and $70.3^{\circ} \mathrm{C}$, and the calculation results of the bubble film opening rate were investigated. The results are shown in Figure 19. The bubble roll-up rate velocity and the bubble lifetime both obeyed the law of $v \sim t^{1 / 3}$. As the temperature of the liquid increased, the speed decreased, and the fitting parameter $c$ decreased from 4.406 to 2.798 and 2.771. Additionally, it could be found that when the temperature increased from $27.6^{\circ} \mathrm{C}$ to $54.9^{\circ} \mathrm{C}$, the roll-up velocity was significantly reduced (the fitting parameter $c$ could be clearly expressed), and when the temperature increased from $54.9^{\circ} \mathrm{C}$ to $70.3^{\circ} \mathrm{C}$, the liquid film curling rate decreased to a small extent. The liquid temperature increased and the bubble cap film cooled. Owing to the Marangoni effect, the discharge rate was reduced, so the film was thicker at rupture, and the roll-up velocity was slower for the same lifetime.

The main reason for this phenomenon was that the increase in temperature caused the surface tension of the liquid to decrease. This was applicable to more than the pure deionized water. When the aerosol was contained in the liquid pool, the increase in temperature caused the surface tension to decrease, which led to a decrease in the speed under the same conditions. However, after the temperature rose to a certain extent, the change in surface tension with temperature was no longer obvious. 

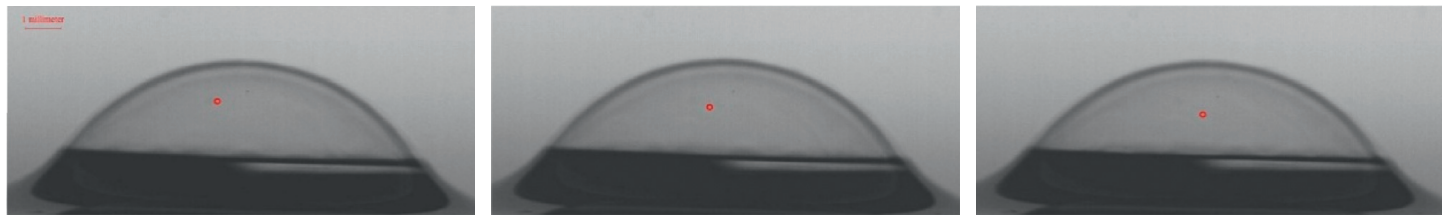

Figure 17: Visualization of particles moving on the cap.
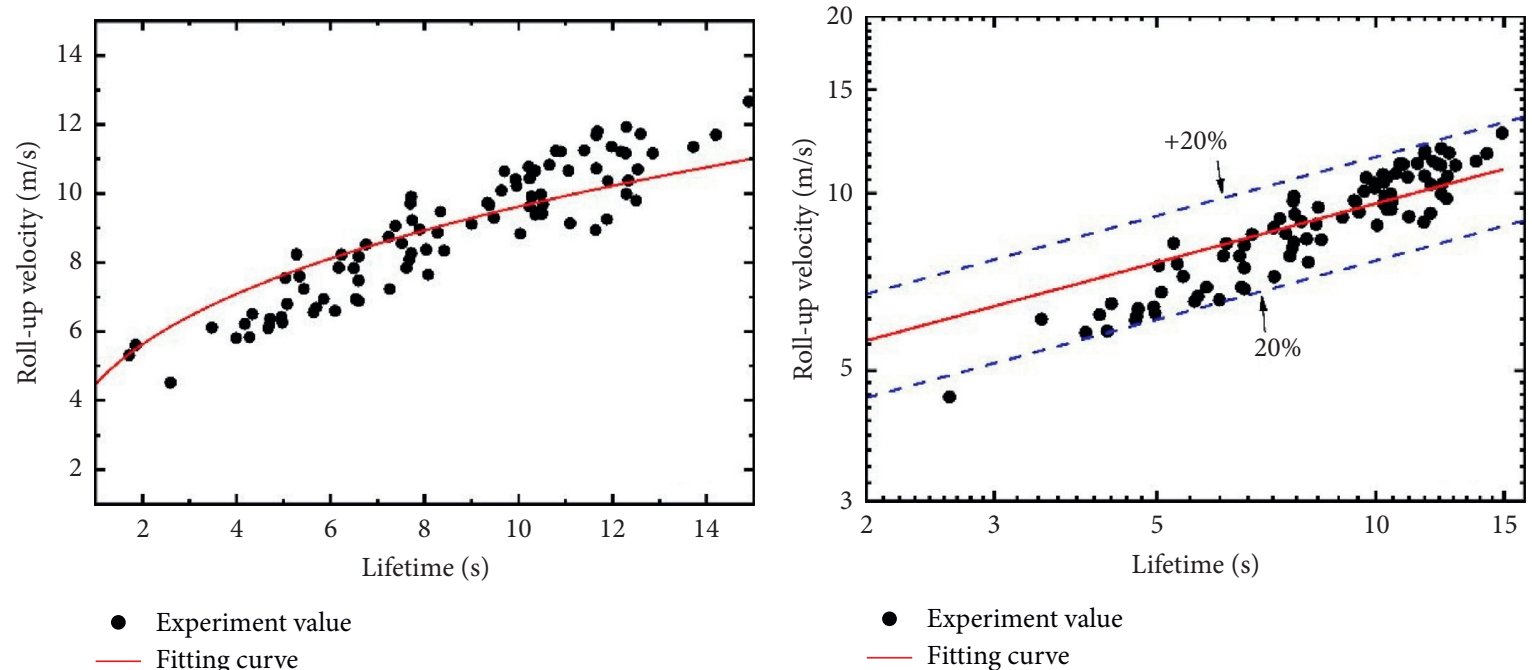

(a)

(b)

FIGURE 18: Correspondence between bubble roll-up velocity and lifetime of $0.05 \mathrm{~g} / \mathrm{L} \mathrm{TiO}_{2}$ aerosol suspension: (a) curve fitting and (b) error analysis.

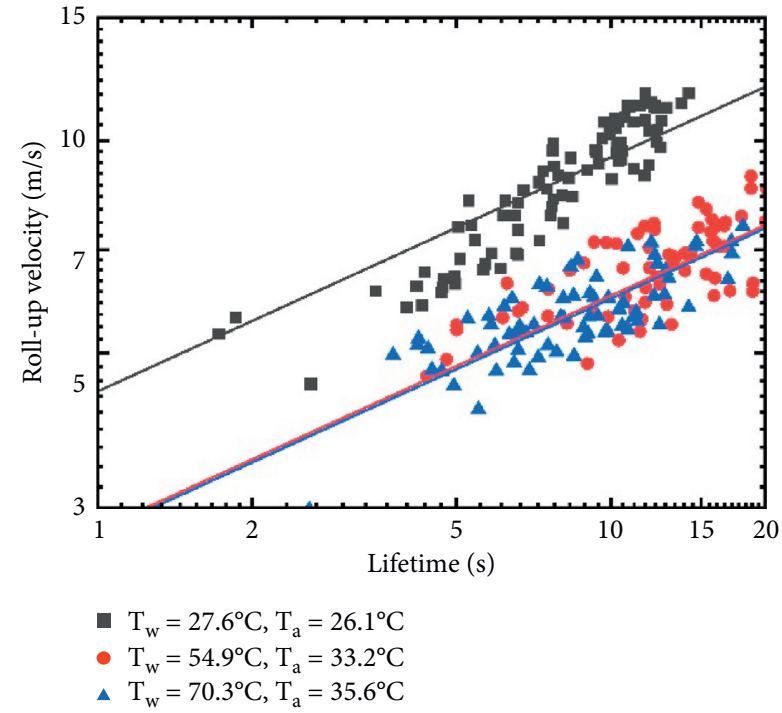

FIGURE 19: Correspondence between bubble roll-up velocity and lifetime of $0.05 \mathrm{~g} / \mathrm{L} \quad \mathrm{TiO}_{2}$ aerosol suspension for different conditions.

To investigate the effect of aerosols on bubble burst characteristics, we compared the film roll-up velocity for the same lifetime. The results are displayed in Figure 20.
It could be found from Figure 20(a) that the liquid film curl rate of the $0.05 \mathrm{~g} / \mathrm{L} \mathrm{TiO}_{2}$ aerosol suspension was higher than that of the deionized water at a liquid temperature of $21.1^{\circ} \mathrm{C}$. The reason for the distinct results was due to the difference in bubble lifetime; fewer bubbles were counted for deionized water conditions with a lifetime higher than $10 \mathrm{~s}$, which was consistent with formula (3). However, after adding the aerosol into the pool, the roll-up velocity increased for the same lifetime. First, the bubble lifetime was significantly increased, the drainage velocity decreased, and it was presumed that the cap film thickness increased. Second, the surface tension was the main driving force at rupture, and the addition of aerosol increased the surface tension, so the roll-up speed increased compared to the increase in thickness. For the case of high temperature shown in Figure 20(b), the increase in temperature reduced the effect of the surface tension, and it seemed that the change of the roll-up velocity was not very obvious.

In fact, the measurement of the surface tension of an aerosol suspension is difficult, and it is impossible to directly calculate the cap film thickness using the speed in an aerosol suspension such as deionized water. The negative correlation between the thickness of the cap and the speed made it possible to characterize the bursting characteristics of the bubble with the roll-up velocity. 


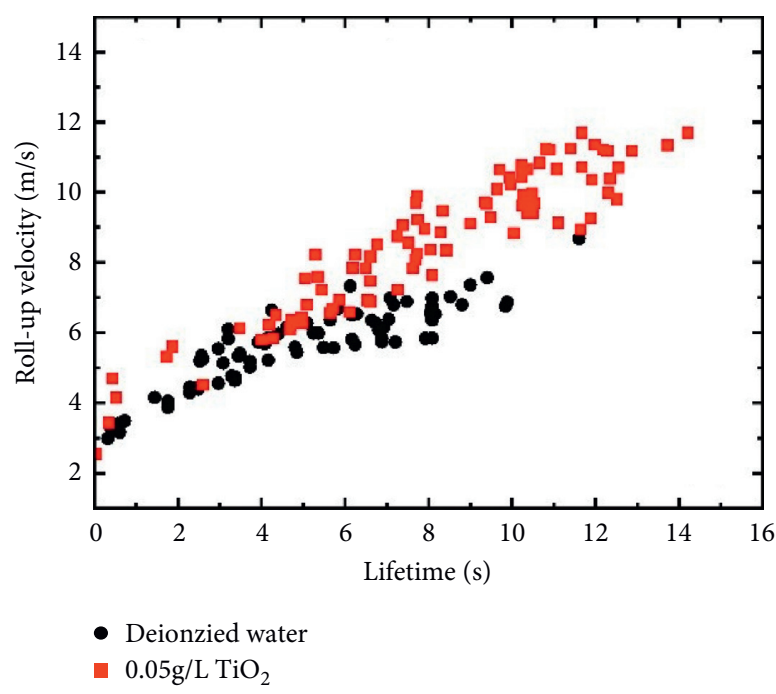

(a)

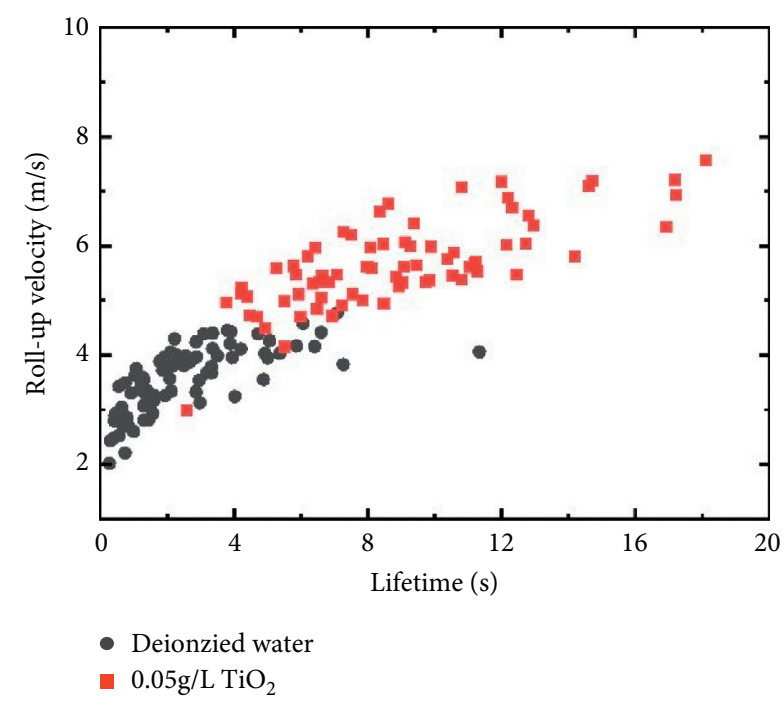

(b)

Figure 20: Correspondence of bubble roll-up velocity and bubble lifetime in different liquid environments: (a) $T_{w}=21.0^{\circ} \mathrm{C}$ and $(\mathrm{b}) T_{w}=71.0^{\circ} \mathrm{C}$.

3.4. Uncertainty Analysis. The frequency of the camera during the lifetime of the bubble was $50 \mathrm{~Hz}$; that is, the time for a single frame of a picture was $1 / 50=0.02 \mathrm{~s}$. After using $\mathrm{PR}$ video processing software to solve the bubble lifetime, the maximum absolute uncertainty was $0.02 \mathrm{~s}$. When the liquid temperature was $19.0^{\circ} \mathrm{C}$, the gas phase was $20.0^{\circ} \mathrm{C}$, the average lifetime of the deionized water was $4.599 \mathrm{~s}$, and the relative uncertainty was $0.02 / 50=0.4 \%$.

The film roll-up velocity was obtained using the average value of the moving distance of the film. Since the position needed to be manually intercepted, there might also have been errors. The uncertainty was calculated with the multiple solution results of the same roll-up velocity. Five measurements results were selected for the same picture in the liquid phase at $19.0^{\circ} \mathrm{C}$, the gas phase at $20.0^{\circ} \mathrm{C}$, and the deionized water. The average value was 5.470 and the root mean square was $12.589 \%$. Hence, the uncertainty was $12.589 \%$.

\section{Conclusion}

Based on the aerosol release characteristics for severe nuclear reactor accidents, a high-speed camera was used to investigate the phenomenon of bubble bursting on the free surfaces of deionized water and aerosol suspensions. The bubble lifetime, roll-up velocity, and cap film thickness were studied. The main conclusions were as follows:

(1) For deionized water, as the liquid temperature increased, the average lifetime first increased and then decreased, and there was a singularity around $45^{\circ} \mathrm{C}$. In a certain range, as the radius of the bubbles increased, the lifetime decreased. The addition of aerosol increased the lifetime, and the change law of the liquid temperature was close to that of deionized water.
(2) The two fitting formulas of the bubble lifetime distribution were applicable to deionized water and aerosol suspensions, and the fitting degrees were generally above $60 \%$. By adding fitting parameters, the formulas also fit well for different liquid temperatures.

(3) The cap film thickness at rupture and the lifetime of the bubble showed an exponential law. As the liquid temperature increased, the cap film at rupture became thicker. As the air temperature increased, the cap film became thinner.

(4) For aerosol suspensions, the bubble roll-up velocity and the bubble lifetime showed an exponential law. As the liquid temperature increased, the velocity decreased significantly, and it was significantly greater than that of the bubbles of deionized water for the same conditions.

\section{Data Availability}

The data used to support the findings of this study are available from the corresponding author upon request.

\section{Conflicts of Interest}

The authors declare that they have no conflicts of interest regarding the publication of this paper.

\section{Acknowledgments}

This work was funded by Central University Basic Scientific Research Business Expenses Special Funds (HEUCFP201855). 


\section{References}

[1] S. Poulain, E. Villermaux, and L. Bourouiba, "Ageing and burst of surface bubbles," Journal of Fluid Mechanics, vol. 851, pp. 636-671, 2018.

[2] S. R. Burger and D. C. Blanchard, "The persistence of air bubbles at a seawater surface," Journal of Geophysical Research, vol. 88, no. C12, pp. 7724-7726, 1983.

[3] E. R. Lewis, E. R. Lewis, R. Lewis, K. E. Karlstrom, and S. E. Schwartz, Sea Salt Aerosol Production: Mechanisms, Methods, Measurements, and Models, American Geophysical Union, Washington, DC, USA, 2004.

[4] M. E. Salter, E. D. Nilsson, A. Butcher, and M. Bilde, "On the seawater temperature dependence of the sea spray aerosol generated by a continuous plunging jet," Journal of Geophysical Research: Atmospheres, vol. 119, no. 14, pp. 90529072, 2014.

[5] C. F. Brasz, C. T. Bartlett, P. L. L. Walls, E. G. Flynn, Y. E. Yu, and J. C. Bird, "Minimum size for the top jet drop from a bursting bubble," Physical Review Fluids, vol. 7, 2018.

[6] R. K. Bagul, D. S. Pilkhwal, P. K. Vijayan, and J. B. Joshi, "Entrainment phenomenon in gas-liquid two-phase flow: a review," Sadhana, vol. 38, no. 6, pp. 1173-1217, 2013.

[7] M. Ouallal, S. Leyer, and S. Gupta, "Literature survey of fission product aerosol re-entrainment modelling," in Proceedings of the 17th International Topical Meeting on Nuclear Reactor Thermal Hydraulics, NURETH 2017, Xi'an, China, September 2017.

[8] K. Mehboob, "Accident source terms for light-water nuclear power plants light-water nuclear power plants," 2012.

[9] M. K. Koch, A. Voßnacke, J. Starflinger, W. Schütz, and H. Unger, "Radionuclide re-entrainment at bubbling water pool surfaces," Journal of Aerosol Science, vol. 31, no. 9, pp. 1015-1028, 2000.

[10] Y. Toba, "Drop production by bursting of air bubbles on the sea surface (II) theoretical study on the shape of floating bubbles," Journal of the Oceanographical Society of Japan, vol. 15, no. 3, pp. 121-130, 1959.

[11] B. A. Puthenveettil, A. Saha, S. Krishnan, and E. J. Hopfinger, "Shape parameters of a floating bubble," Physics of Fluids, vol. 30, 2018.

[12] C. T. Nguyen, H. M. Gonnermann, Y. Chen et al., "Film drainage and the lifetime of bubbles," Geochemistry, Geophysics, Geosystems, vol. 14, no. 9, pp. 3616-3631, 2013.

[13] J. Miguet, M. Pasquet, F. Rouyer, Y. Fang, and E. Rio, "Stability of big surface bubbles: impact of evaporation and bubble size," Soft Matter, vol. 16, no. 4, pp. 1082-1090, 2020.

[14] Q. A. Zheng, V. Klemas, and Y.-H. L. Hsu, "Laboratory measurement of water surface bubble life time," Journal of Geophysical Research, vol. 88, no. C1, pp. 701-706, 1983.

[15] A. Vrij and J. T. G. Overbeek, "Rupture of thin liquid films due to spontaneous fluctuations in thickness," Journal of the American Chemical Society, vol. 90, no. 12, pp. 3074-3078, 1968.

[16] H. Lhuissier and E. Villermaux, "Bursting bubble aerosols," Journal of Fluid Mechanics, vol. 696, pp. 5-44, 2012.

[17] L. Champougny, M. Roché, W. Drenckhan, and E. Rio, "Life and death of not so "bare" bubbles," Soft Matter, vol. 12, no. 24, pp. 5276-5284, 2016.

[18] J. Cosandey, Droplet Production over a Boiling Pool during a Slow Depressurization, ETH Zurich, Zurich, Switzerland, 1999.
[19] D. E. Spiel, "On the births of film drops from bubbles bursting on seawater surfaces," Journal of Geophysical Research: Oceans, vol. 103, no. C11, pp. 24907-24918, 1998.

[20] F. Resch and G. Afeti, "Film drop distributions from bubbles bursting in seawater," Journal of Geophysical Research: Oceans, vol. 96, pp. 10681-1068, 1991.

[21] H. Chen, H. Gu, X. Yu, Y. Zhou, Z. Sun, and J. Wen, "Experimental study on bubble bursting and droplet releasing characteristics under different liquid phase conditions," in 2018 26th International Conference on Nuclear Engineering, American Society of Mechanical Engineers Digital Collection, London, UK, July 2018.

[22] F. E. C. Culick, "Comments on a ruptured soap film," Journal of Applied Physics, vol. 31, no. 6, pp. 1128-1129, 1960.

[23] W.-R. Ke, Y.-M. Kuo, C.-W. Lin, S.-H. Huang, and C.-C. Chen, "Characterization of aerosol emissions from single bubble bursting," Journal of Aerosol Science, vol. 109, pp. 1-12, 2017.

[24] D. E. Spiel, "A hypothesis concerning the peak in film drop production as a function of bubble size," Journal of Geophysical Research: Oceans, vol. 102, no. C1, pp. 1153-1161, 1997. 